\title{
Aprendizagem e desenvolvimento profissional de professores iniciantes que participam de comunidades investigativas
}

\author{
Learning and professional development of novice teachers who participate in research \\ communities
}

Ana Leticia Losano ${ }^{1}$

\begin{abstract}
Resumo
Os primeiros anos de exercício profissional nas escolas constituem uma etapa conflitiva, marcada por tensões e contradições entre princípios, ideais e experiências vividas durante a formação inicial e demandas, desafios e restrições da prática docente nas escolas. Nesse cenário, o presente artigo visa descrever e compreender a aprendizagem e o desenvolvimento profissional de professores iniciantes que participam de comunidades investigativas. A pesquisa toma por foco um grupo colaborativo formado por seis professores iniciantes e duas professoras universitárias. Utilizando uma metodologia qualitativa, o estudo desenvolve uma análise narrativa que detalha e analisa episódios que envolveram os membros da comunidade no planejamento, na implementação em sala de aula e na reflexão de uma tarefa centrada na interpretação de gráficos. O resultado evidencia as potencialidades da participação em comunidades investigativas para a aprendizagem e o desenvolvimento profissional dos professores iniciantes.
\end{abstract}

Palavras-chave: Professores iniciantes; Comunidades investigativas; Aprendizagem docente; Desenvolvimento profissional.

\begin{abstract}
The first years of professional practice in schools are a conflictive period in mathematics teachers' professional lives, generally marked by tensions and contradictions between the principles, ideals and experiences encountered during pre-service education and the demands, challenges and restrictions of their teaching practice in schools. The aim of this article is to describe and understand the learning and professional development of novice teachers who participate in research communities. The research focuses on a research community formed by six novice teachers and two university teachers. Using a qualitative methodology, we developed a narrative analysis of episodes that engaged the community members on planning, implementing and reflecting about a classroom activity centered on graphic interpretation. The analysis shows the potentialities of participating in such communities for fostering novice teachers learning and professional development.
\end{abstract}

Keywords: Novice teachers; research communities; teachers' learning; professional development.

\section{Introdução}

Os primeiros anos de exercício profissional docente são considerados pela literatura sobre formação de professores como uma etapa problemática, complexa e de grande relevância (Goos et al., 2009; Lerman, 2009). É uma fase significativa na carreira de todo

Submetido em: 06/10/2017 - Aceito em: 30/07/2018 - Publicado em: 08/08/2018

${ }^{1}$ Doutora em Ciencias de la Educación pela Universidad Nacional de Córdoba, Argentina. Professora da Universidad Nacional de Córdoba, Argentina. Email: letilosano@gmail.com 
professor, geralmente caraterizada por sentimentos conflitivos como alegria, entusiasmo, medo e insegurança. Segundo Rocha e Fiorentini (2009), ao iniciar a docência, o professor se depara com "uma prática complexa que o leva a problematizar e colocar em xeque suas crenças, suas concepções e os saberes construídos até então" (p. 125-126). Winslow et al. (2009) assinalam que, no começo do exercício profissional, coexistem, pelo menos, três processos inter-relacionados:

- Processos epistemológicos, relacionados com a ressignificação dos conhecimentos disciplinares e pedagógicos aprendidos na formação inicial em função das experiências na prática profissional.

- Processos sociais, vinculados à participação em diferentes ambientes institucionais.

- Processos pessoais, pautados pela mudança de ser um estudante para ser um professor.

Conforme Gama (2009), os primeiros anos de exercício profissional estão marcados tanto pelo sentimento de sobrevivência - desencadeado quando o professor iniciante deve enfrentar situações complexas nunca antes vivenciadas - quanto pelo de descoberta caraterizado pelo entusiasmo inicial de estar encarregado da sua própria sala de aula e de ser parte de um corpo profissional. Segundo a autora, esses sentimentos "constituem-se em desafios para a continuidade na carreira e para o desenvolvimento profissional da grande maioria dos professores iniciantes" (p. 102).

Podemos dizer, então, que os professores iniciantes enfrentam contínuas tensões e contradições entre os princípios, os ideais e as experiências vividas durante a formação inicial e as demandas, os desafios e as restrições da prática docente nas escolas (Walshaw, 2012). Na presente pesquisa, considero que os primeiros anos de exercício profissional são uma etapa da vida profissional dos professores na qual entram em jogo as experiências passadas, principalmente aquelas vividas durante a formação inicial -, em confronto com aquelas do presente, imaginando as práticas que gostariam de desenvolver em suas aulas no futuro. (Losano, Fiorentini, \& Villarreal, 2018).

Diversos autores salientam que a participação em comunidades investigativas ou grupos colaborativos pode constituir-se numa oportunidade frutífera para apoiar os professores iniciantes, visto que esses grupos oferecem espaços para a reflexão crítica das experiências, múltiplas e contraditórias, vividas nos primeiros anos de exercício docente (Gama, 2009; Gama \& Fiorentini, 2008; Losano et al., 2018).

Segundo Goos (2005), um grande desafio para as pesquisas sobre formação de professores de matemática é compreender como esses profissionais aprendem a partir de suas experiências em múltiplos contextos, principalmente quando sua própria escolaridade, a formação inicial e as experiências profissionais iniciais produzem imagens conflituosas do ensino da matemática. Seguindo essa direção, a presente pesquisa tem por objetivo descrever e compreender a aprendizagem e o desenvolvimento profissional de professores iniciantes 
que participam de comunidades investigativas, centradas na reflexão sobre a prática docente em matemática.

$\mathrm{O}$ artigo está organizado da seguinte maneira. Na próxima seção, apresento a fundamentação teórica do estudo, baseada nas noções de desenvolvimento profissional, comunidades investigativas e aprendizagem situada na participação na prática. Na sequência, descrevo o grupo colaborativo que foi o contexto da pesquisa. A seguir, detalho os procedimentos metodológicos utilizados. Na seção seguinte desenvolvo a análise. E finalizo, tecendo algumas conclusões que destacam as potencialidades da participação em comunidades investigativas para a aprendizagem e o desenvolvimento profissional de professores iniciantes.

\section{Fundamentação teórica}

A noção de desenvolvimento profissional docente, adotada nesta pesquisa, surge em resposta a maneiras "tradicionais" de compreender a formação de professores nas quais, através de um movimento de fora para dentro, eles "adquirem a forma" esperada pela sociedade ou pelas instituições (Fiorentini \& Crecci, 2013; Ponte, 1998). Desse modo, introduz-se uma nova perspectiva para olhar a formação docente que compreende o professor como capaz de gerir sua aprendizagem e de ser o principal protagonista de sua educação e da sua cultura profissional (Ponte, 1998).

Enfatiza-se, assim, o "processo contínuo que se estende ao longo da vida profissional da pessoa e que começa antes de obter o diploma na graduação" (Fiorentini, 2013, p. 161). Trata-se de um processo não linear e inacabado, que pode tomar muitas formas (Ferreira, 2008; Rocha \& Fiorentini, 2009) e que está "integrado às práticas sociais e aos cotidianos escolares de cada um" (Passos et al., 2006, p. 195). Day (1999) sublinha que o desenvolvimento profissional inclui as aprendizagens desenvolvidas tanto no âmbito "privado" da sala de aula - aprendizagens que ajudam ao professor a sobreviver e a tornar-se competente dentro da sala - como aquelas adquiridas em instâncias formativas formais e informais. Assim, o desenvolvimento profissional permite englobar as aprendizagens produzidas durante a formação inicial, a iniciação à docência e a formação continuada (Rocha \& Fiorentini, 2009).

Para Guérios (2005), a noção de desenvolvimento profissional permite interrelacionar a formação inicial do professor e os primeiros anos de exercício profissional, visto que entende a formação como um movimento de "chegar a ser um professor". O início do exercício profissional, quando se passa de aluno a professor, é uma etapa significativa no desenvolvimento profissional dos professores de matemática (Rocha \& Fiorentini, 2009). No presente artigo, viso analisar como acontece essa passagem no caso de professores iniciantes que participam de uma comunidade investigativa.

O desenvolvimento profissional salienta o "processo contínuo de constituição do sujeito, ao longo do tempo, principalmente em uma comunidade profissional" (Fiorentini \& Crecci, 2013, p. 13). Ao iniciar seu exercício profissional, os professores iniciantes começam Zetetiké, Campinas, SP, v.26, n.3, set./dez.2018, p.441-463 
a participar de diferentes comunidades profissionais - as escolas nas quais começam a lecionar, os cursos de formação continuada, grupos de estudo, etc. - as quais perseguem objetivos múltiplos e, frequentemente, em conflito. Embora esses diversos grupos possam contribuir para o processo de constituição dos professores iniciantes, eles não necessariamente se organizam em torno da ideia de potencializar o desenvolvimento profissional deles. Segundo Kieran, Krainer e Shaughnessy (2013), aquelas comunidades que perseguem essa finalidade - comumente chamadas "comunidades investigativas" - podem ser caraterizadas através de três dimensões centrais. Em primeiro lugar, uma dimensão reflexiva, isto é, as comunidades investigativas promovem uma reflexão colaborativa orientada à pesquisa sobre a prática docente. Essa reflexão permite que os participantes questionem, explorem e busquem alternativas sobre seus enfoques de ensino, transformando sua visão da prática docente. Em segundo lugar, uma dimensão pesquisa-ação, ou seja, os participantes comprometem-se com a pesquisa sistemática sobre a própria prática, visando aprender sobre ela e transformá-la. Finalmente, a dimensão que ressalta a dualidade entre a pesquisa e o desenvolvimento profissional: a reflexão sobre a prática envolve desenvolvimento profissional, porque traz para o primeiro plano os conhecimentos que os participantes adquirem através de sua experiência e explicita conhecimentos que costumam permanecer implícitos.

Assim sendo, as práticas desenvolvidas nestas comunidades visam ao desenvolvimento de posturas questionadoras e críticas sobre as práticas docentes de todos seus membros. Nas palavras de Jaworski (2008),

Numa comunidade investigativa não estamos satisfeitos com o estado normal (desejável), mas nos aproximamos da nossa prática com uma atitude questionadora, não para mudar tudo da noite para o dia, mas para começar a explorar o que é possível; para questionar-nos, para fazer perguntas e para buscar compreender colaborando com outros. (pp. 313-314).

Seguindo essa direção, a autora elaborou a noção de "alinhamento crítico" que reconhece ser essencial ocorrer, dentro das práticas existentes nas escolas, um certo alinhamento, agora, se for agregada a ele uma atitude crítica - através do questionamento, da exploração da busca de alternativas, então se torna possível desenvolver e mudar o status quo das instituições educativas onde o professor atua. Entender isso é particularmente relevante quando se trata de professores iniciantes que, ao longo das suas primeiras experiências na prática, tomam contato com as práticas estabelecidas e legitimadas nas diferentes comunidades escolares onde começam a trabalhar.

É importante ressaltar que as comunidades investigativas não nascem "já prontas", mas vão sendo constituídas ao longo do tempo. É justamente o comprometimento com a "problematização, a desnaturalização do que se ensina e se aprende na escola e que aparentemente parece ser o normal" (Fiorentini, 2013, pp. 160-161) a marca fundamental de seu desenvolvimento.

Esses processos de questionamento, teorização e sistematização da própria prática docente envolvem múltiplas aprendizagens para os professores. Com base em Lave e Wenger 
(1991) e Wenger (1998), entendemos essas aprendizagens como situadas histórica, social e culturalmente na participação em comunidades. Assim, a aprendizagem docente está situada na participação em diferentes práticas - tais como ministrar aulas na escola, assistir a reuniões de professores, realizar um curso de formação continuada, participar de um grupo colaborativo, etc.-, todas elas organizadas social e culturalmente e com um desenvolvimento histórico que lhes outorga forma e sentido.

Ao participar da prática docente nas comunidades escolares, o professor desenvolve conhecimentos experienciais situados nas particularidades da vida cotidiana nas escolas e nas salas de aula e que se manifestam nas ações, nas decisões e nos julgamentos que ele desenvolve na prática. Esses conhecimentos, carregados de valores, finalidades e sentidos, são fundamentais para desenvolver suas práticas docentes. Contudo, eles podem se tornar naturais e válidos por si mesmos em virtude da rotina e da naturalização do cotidiano escolar, o que ocultaria desvios, ideologias e relações de poder (Fiorentini, 2013; Fiorentini \& Carvalho, 2015).

As comunidades investigativas, tais como as descritas por Fiorentini (2009), Jaworski (2008) e Kieran et al. (2013), entre outros, desenvolvem práticas justamente com foco na reflexão e na problematização desses conhecimentos aprendidos na prática. Essas comunidades, que frequentemente reúnem professores da escola e da universidade, estão baseadas na ideia de coaprendizagem, ou seja, na ideia de que professores da escola e da universidade podem aprender sobre o mundo do outro, mas também sobre o seu próprio mundo (Wagner, 1997). As comunidades investigativas permitem, então, a interseção de dois mundos frequentemente separados, possibilitando a construção de relações sinergéticas entre a pesquisa e a prática (Kieran et al., 2013). Particularmente, neste estudo, estou interessada em analisar os processos de aprendizagem de professores iniciantes, ao participar em uma comunidade investigativa, a qual é descrita a seguir.

\section{$O$ contexto de aprendizagem e de desenvolvimento profissional}

O Grupo colaborativo de reflexão e transformação da prática docente em matemática teve origem no início de 2014, e seus membros continuam se reunindo até a atualidade. No início, foi formado por seis professores iniciantes - Melania, Damián, Araceli, Carlos, Yanela e Liliana - e duas professoras universitárias - Mónica e Letícia, autora deste artigo. As reuniões do grupo acontecem quinzenalmente na Faculdade de Matemática, Astronomia, Física e Computação da Universidade Nacional de Córdoba (Argentina). Todos os professores iniciantes são graduados em Licenciatura em Matemática, oferecida por essa faculdade, sendo quatro deles da turma de 2012 e dois da de 2013. Como as professoras universitárias tinham sido suas professoras em algumas das disciplinas da graduação (Didática da Matemática e/ou Estágio Supervisionado), quando o grupo começou a se reunir, seus participantes já tinham compartilhado numerosas reflexões e discussões sobre o ensino e a aprendizagem da matemática e, do mesmo modo, vivenciado, conjuntamente, experiências formativas significativas, tais como o estágio supervisionado. Assim sendo, ao voltar à 
universidade e reencontrar-se com seus pares e antigos docentes, os professores iniciantes podiam compartilhar suas frustrações e suas alegrias, assim como constatar que as dificuldades e as necessidades profissionais não eram individuais, mas comuns a muitos deles (Gama, 2009).

Ao longo do tempo, o grupo desenvolveu diversas atividades, todas fortemente vinculadas com a prática docente de seus membros. Por exemplo, analisamos os planejamentos anuais de vários dos professores iniciantes e elaboramos e implementamos tarefas para sala de aula com foco na análise de gráficos, na função de proporcionalidade direta, nas transformações de funções trigonométricas, na função exponencial e nos números irracionais. Cada uma dessas tarefas foi desenvolvida através das seguintes fases:

- Uma primeira versão da tarefa era elaborada por alguns membros do grupo particularmente interessados na temática.

- Essa primeira versão era discutida em profundidade em uma reunião com todos os membros do grupo, quando consideradas necessárias sugeriam-se modificações, o que dava origem a uma segunda versão da tarefa.

- A tarefa era implementada em sala de aula. Em alguns casos, com a colaboração de outros membros do grupo.

- Uma análise posterior à implementação era feita dentro do grupo, guiada pela reflexão dos professores sobre suas próprias práticas e as dos outros.

Outras atividades, tendo por foco a comunicação das experiências vividas dentro, e a partir, do grupo foram compartilhadas com outros professores e pesquisadores, como por exemplo, na participação em congressos (Cabrera, 2015; Cecchetto, Coirini, \& Colazo, 2015; Losano, Cabera, \& Giannone, 2015), na criação da página web do grupo ${ }^{2}$ - onde aparecem todas as tarefas elaboradas assim como algumas orientações para professores que desejem implementá-las - e na escrita de um capítulo de livro (Losano et al., 2017).

A escrita de textos narrativos também foi uma atividade que nos proporcionou refletir sobre nossas trajetórias profissionais e as expectativas que temos para com o grupo. Em muitas dessas escritas, os professores iniciantes narravam, em primeira pessoa e com suas próprias palavras, muitos dos conflitos e dos dilemas, presentes nas primeiras experiencias na atuação docente, mencionados na introdução deste artigo:

Tentei fazer com que algumas aulas fossem "investigativas" [ênfase no original], instigando os estudantes a produzir matemática, a tentar descobrir novos conhecimentos a partir dos que já adquiriram; mas me deparei com o fato de que eles não têm vontade. Eles querem que eu fale exatamente o que eles têm que fazer ${ }^{3}$. (Narrativa de Melania).

\footnotetext{
${ }^{2}$ A página web do grupo encontra-se em permanente construção. Ela pode ser visitada em: https://grupocolaboramate.wordpress.com/

${ }^{3}$ Todas as citações incluídas neste artigo foram traduzidas do espanhol para o português pela autora deste artigo.
} 
Estou passando por muita coisa, e tenho coisas demais para aprender ainda ... me senti pouco apoiado em uma das escolas onde trabalho, e isso me desanima bastante. (Narrativa de Damián).

[Relatando seu primeiro dia como professora]. E chegou a quarta-feira, às $9 \mathrm{~h}$ já estava na escola. Antes que a campainha tocasse, a vice-diretora me disse que tinha que fazer um "contrato didático" [ênfase no original] com cada uma das turmas e que ela ia me apresentar aos alunos. Entrei em pânico, porque não estava nos meus planos fazer o tal contrato. ... Finalizada a apresentação um dos alunos me disse: "professora nem pense em fazer nenhum contrato didático, já chega disso!”. (Narrativa de Araceli).

Essas palavras colocam no primeiro plano o fato de que os processos sociais, pessoais e epistemológicos, mencionados por Winslow et al. (2009), envolvem enfrentar uma multiplicidade de tensões e conflitos. O grupo colaborativo era, então, um espaço onde os professores iniciantes podiam compartilhar essas inquietações e refletir sobre elas junto com outros colegas e com a professores da universidade.

Isso posto, a descrição das atividades do grupo me leva a caracterizá-lo como uma comunidade investigativa, visto que nela se "desenvolvem, num entorno colaborativo, estudos, análises, pesquisa e escrita de artigos sobre o processo de ensinar e aprender matemática na escola" (Fiorentini, 2013, p. 154).

\section{Abordagem metodológica}

A presente pesquisa adota uma metodologia qualitativa dentro do paradigma interpretativo (Rockwell, 2009). Esse tipo de metodologia é adequado para o problema de pesquisa, porque ela permite "a compreensão interpretativa das experiências individuais dentro do contexto em que foram vivenciadas" (Goldenberg, 2011, p. 19). Assim, procuramos analisar as experiências de participação em uma comunidade investigativa tal como elas foram vistas e vividas pelos atores participantes: os professores iniciantes (Ponte, 2006). É importante mencionar que, atualmente, as perspectivas qualitativas têm sido amplamente utilizadas para pesquisar a formação de professores dentro da Educação Matemática (Gellert, Becerra, \& Chapman, 2013).

Fazendo uso dessa abordagem metodológica e a partir da perspectiva teórica apresentada, o presente estudo possui como pergunta norteadora: Que aprendizagens são evidenciados pelos professores iniciantes que participam de uma comunidade investigativa e como eles se desenvolvem profissionalmente através da participação nessa comunidade?

Segundo Fiorentini (2013), o pesquisador interessado em estudar o desenvolvimento dos professores deve considerar o contexto, a prática e as interações que podem ter contribuído para o processo de tornar-se professor. No presente estudo, focalizo a análise nas práticas e nas interações que tiveram lugar na comunidade investigativa no ano 2014 e que envolveram seus membros no planejamento, na implementação em sala de aula e na reflexão de uma tarefa centrada na interpretação de gráficos. Diversas razões justificam esse recorte. Em primeiro lugar, essa foi uma das primeiras vezes que a comunidade se envolveu em um ciclo de criação, implementação e reflexão colaborativa de tarefas para sala de aula. Em 
segundo lugar, porque a implementação da tarefa envolveu não somente a professora iniciante encarregada das turmas na escola - Araceli -, mas também dois membros do grupo que ainda não tinham começado seu exercício profissional - Liliana, recentemente graduada, e Yanela que estava concluindo a formação inicial. Finalmente, porque a experiência de participação nessas práticas mobilizou as professoras a produzir escritos que, posteriormente, foram apresentados em congressos e que fizeram parte de um capítulo de livro. Esse recorte permite, então, analisar como Yanela, Araceli e Liliana se envolveram na pesquisa sobre sua própria prática docente a partir da participação na comunidade investigativa.

Os dados analisados compreendem processos de participação nas reuniões do grupo destinadas à análise e à reflexão sobre a tarefa ${ }^{4}$, assim como as reificações produzidas pelas professoras ao longo de todo o processo. A Tabela 1 descreve e resume a informação referente aos dados, incluindo data, descrição da atividade e contexto.

Tabela 1 - Descrição dos dados.

\begin{tabular}{|c|c|c|c|}
\hline Fonte & Data & Atividade & Contexto \\
\hline $\begin{array}{l}\text { Arquivo de } \\
\text { Áudio }\end{array}$ & $\begin{array}{l}1 \text { de julho de } \\
2014\end{array}$ & $\begin{array}{l}\text { Discussão da primeira } \\
\text { versão da tarefa elaborada } \\
\text { por Liliana, Araceli e } \\
\text { Yanela }\end{array}$ & Reunião do grupo colaborativo \\
\hline $\begin{array}{l}\text { Arquivo de } \\
\text { Áudio }\end{array}$ & $\begin{array}{c}9 \text { de } \\
\text { setembro de } \\
2014\end{array}$ & $\begin{array}{l}\text { Análise e reflexão sobre a } \\
\text { implementação da tarefa em } \\
\text { sala de aula }\end{array}$ & Reunião do grupo colaborativo \\
\hline $\begin{array}{c}\text { Narrativa } \\
\text { escrita }\end{array}$ & $\begin{array}{c}\text { Março de } \\
2015\end{array}$ & $\begin{array}{l}\text { Expectativas para o novo } \\
\text { ano, considerando os } \\
\text { aportes da participação no } \\
\text { grupo no ano anterior }\end{array}$ & $\begin{array}{l}\text { Cada participante escreveu uma } \\
\text { narrativa, as quais foram lidas e } \\
\text { discutidas durante a primeira reunião do } \\
\text { grupo em } 2015\end{array}$ \\
\hline $\begin{array}{c}\text { Cecchetto, } \\
\text { Coirini \& } \\
\text { Colazo } \\
(2015)\end{array}$ & $\begin{array}{c}\text { Setembro de } \\
2015\end{array}$ & $\begin{array}{l}\text { Proposta de ensino: } \\
\text { apresentação da tarefa, } \\
\text { relato da implementação e } \\
\text { reflexão }\end{array}$ & $\begin{array}{l}\text { XXXVIII Reunión de Educación } \\
\text { Matemática, realizada em Santa Fe, } \\
\text { Argentina. }\end{array}$ \\
\hline $\begin{array}{l}\text { Losano et } \\
\text { al. (2017) }\end{array}$ & $\begin{array}{c}\text { Dezembro } \\
\text { de } 2016\end{array}$ & $\begin{array}{l}\text { Seção dentro de um } \\
\text { capítulo de livro, no qual as } \\
\text { professoras refletem sobre } \\
\text { as contribuições da } \\
\text { experiência para o seu } \\
\text { desenvolvimento } \\
\text { profissional }\end{array}$ & $\begin{array}{l}\text { "Desarrollo professional de profesores } \\
\text { de matemática: experiencias de } \\
\text { participación en un grupo colaborativo } \\
\text { durante los primeiros años de ejercicio } \\
\text { docente" capítulo do livro "Formación } \\
\text { de profesores que enseñan matemática y } \\
\text { práticas educativas en diferentes } \\
\text { escenários: Aportes para la educación } \\
\text { matemática", que reúne os trabalhos } \\
\text { desenvolvidos pelo Grupo de Enseñanza } \\
\text { de la Ciencia y la Tecnologia da } \\
\text { FaMAF-UNC }\end{array}$ \\
\hline
\end{tabular}

Fonte: O autor.

\footnotetext{
${ }^{4}$ É importante ressaltar que essas não foram as únicas reuniões do grupo. Tal como descrito na seção anterior, o grupo se reúne quinzenalmente. Para este artigo, selecionamos apenas aqueles encontros nos quais foi discutida a tarefa centrada na interpretação de gráficos.
} 
Com a intenção de desenvolver uma análise que pudesse colocar em primeiro lugar as vozes dos participantes e capturar as suas aprendizagens e desenvolvimento, decidi por uma análise narrativa dos dados (Riessman, 2002, 2005). Esse tipo de análise é particularmente apropriado já que os dados coletados possuem uma natureza narrativa. Assim, tanto nas reuniões do grupo como nas narrativas escritas ou nos textos elaborados para comunicação e publicação do trabalho realizado, as professoras iniciantes selecionaram, organizaram e conectaram um conjunto de episódios que elas consideraram relevantes para uma audiência particular (Riessman, 2005). Segundo Fiorentini (2013), a análise narrativa, que reúne as interpretações do pesquisador e as do professor em torno de eventos que impactaram na prática docente, é uma importante ferramenta metodológica para descrever situações de aprendizagem e revelar sinais de desenvolvimento profissional.

Depois da leitura reiterada dos diferentes dados, foi possível selecionar um conjunto de episódios, ou seja, eleger "um entorno onde acontece um evento (Bakhtin, 1984) em torno do qual um grupo de participantes interage, produzindo e negociando sentidos em relação a esse evento" (Losano et al., 2018, p. 297 ). A seleção dos episódios realizou-se com base na pergunta norteadora da pesquisa. Desse modo, os episódios, nos quais estava interessada, eram aqueles que aconteceram dentro - ou a partir - da participação na comunidade investigativa e que, tomados em conjunto, permitissem narrar as aprendizagens evidenciadas pelas professoras iniciantes assim como também seu processo de desenvolvimento. Em muitos desses episódios, as professoras adotaram uma visão retrospectiva, ou seja, refletiram sobre elas mesmas como professoras, sobre suas práticas e sobre sua participação no grupo (Bjuland, Cestari, \& Borgersen, 2012).

É importante ressaltar que, ao mesmo tempo em que cada um desses episódios está estreitamente vinculado ao contexto sociocultural onde aconteceram, eles também estão ligados ao passado, ao presente e às projeções de futuro das pessoas que os vivenciaram. Isso significa que, embora os episódios tenham acontecido em um período de aproximadamente dois anos, eles englobam uma temporalidade maior, pois as práticas vindas do passado particularmente aquelas vividas durante a formação inicial - eram neles resgatadas e ressignificadas.

Segundo Clandinin e Connelly (2000), uma "boa pesquisa narrativa" (p. 185) deve satisfazer os critérios de autenticidade, adequabilidade e plausibilidade, bem como qualidade explicativa e convidativa à elucidação da experiência investigada. Esses critérios envolvem o desenvolvimento de relações de confiança mútua entre os pesquisadores e os participantes da pesquisa, uma relação na qual eles trabalhem colaborativamente para elucidar e compreender o fenômeno pesquisado. Para atender especialmente o critério da autenticidade, versões preliminares da análise dos dados foram compartilhadas com os participantes da pesquisa, oferecendo-lhes a oportunidade de propor mudanças e correções. A análise narrativa das aprendizagens e do desenvolvimento dos professores iniciantes a partir da participação nas práticas desenvolvidas pelo grupo em torno da tarefa de interpretação de gráficos é apresentada a seguir. 


\section{Análise narrativa}

A tarefa teve origem nas preocupações de Araceli, que estava completando o seu segundo ano como professora. Segundo suas palavras, "já fazia um tempo que estava querendo vincular à matemática com a vida cotidiana" (Losano et al., 2017, p. 63). Com essa intenção, ela propôs ao grupo a possibilidade de desenvolver uma atividade para analisar gráficos, incluídos em notícias de jornais. Liliana e Yanela ficaram interessadas na proposta e se dispuseram a colaborar com Araceli. As três realizaram uma busca em diferentes jornais, procurando por notícias que incluíssem gráficos. Paralelo a isso, leram diversos estudos que discutiam o ensino da representação gráfica de relações entre variáveis e a interpretação de gráficos cartesianos. Esse trabalho deu origem a uma tarefa, na qual os estudantes deviam analisar distintos tipos de gráficos de relações elaborados a partir de contextos de realidade e de semirrealidade. O objetivo que perseguiam era "fomentar, nos estudantes, o desenvolvimento de uma atitude crítica" (Cecchetto et al., 2015, p. 3). Ao formular o objetivo para a tarefa, Araceli, Liliana e Yanela utilizaram termos provenientes da perspectiva da Educação Matemática Crítica (Skovsmose, 2014), que conheceram durante sua formação inicial. Assim, a elaboração da tarefa dentro do grupo colaborativo foi uma oportunidade para que as professoras iniciantes recuperassem experiências vividas na formação inicial e as ressignificassem, atuando agora como professoras na escola.

A tarefa, como um todo, estava dividida em três atividades. Aqui irei focar na elaboração, na implementação e na reflexão da primeira delas. Essa atividade destacava uma notícia publicada em março de 2014 no jornal La voz del interior - principal jornal do estado de Córdoba - que discutia o aumento do preço da cesta básica. É importante ressaltar que, naquele momento, na Argentina, o cálculo do preço da cesta básica estava no centro de árduos debates. Assim, eram frequentes as notícias em que políticos, economistas e jornalistas criticavam ou desprestigiavam os procedimentos que os organismos oficiais utilizavam para calcular esse indicador da economia. A notícia escolhida apresentava os resultados de um levantamento feito pelo próprio jornal em quatro supermercados da cidade de Córdoba, a respeito dos preços de certos produtos que compõem a cesta básica na Argentina. Entre outras coisas, o texto ressaltava a relação entre o valor da cesta básica e o salário de um trabalhador do setor privado e discutia o aumento dos preços da carne, das frutas e dos legumes (vide Quadro 1). A notícia finalizava com uma série de gráficos, representando a evolução dos preços por item da cesta básica, assim como com um gráfico da evolução do preço total da cesta básica (vide Figura 1). 
Quadro 1 - Notícia do Jornal La voz del interior, utilizada para desenvolver a tarefa ${ }^{5}$

\section{Supermercado \\ O maior aumento de preços em quatro anos \\ A cesta básica para quatro pessoas aumentou em $7,6 \%$ em fevereiro e chegou aos $\$ 3.257,26$. Os preços da carne e dos legumes dispararam apesar das tentativas de freia-los}

As tentativas oficiais para conter os preços dos alimentos ainda não se veem refletidas nos tickets. Pelo contrário, em fevereiro subiram mais do que em janeiro, nos dias seguintes à desvalorização da moeda, e ficaram $7,6 \%$ mais caros.

Trata-se da maior subida de preços na cesta básica que $\boldsymbol{L} \boldsymbol{a}$ voz del interior releva mensalmente em quatro supermercados (Carrefour, Wall Mart, Libertad e Disco), quando os preços dispararam $8,4 \%$. Daquela vez, com uma alta demanda e uma queda na oferta, a carne foi a principal culpada da variação.

Hoje, uma família de dois adultos e duas crianças precisa $\$ 3.257,26$ para comprar os alimentos e os produtos de limpeza do mês, 230,57 mais do que no mês passado. Nesse ano, já registra um aumento de $13 \%$, depois da subida de $5 \%$ em janeiro de 7,6\% agora.

Até definir novos acordos salariais, os gastos do supermercado representam mais da metade $(52,1 \%)$ dos ingressos de um trabalhador do setor privado. Em Córdoba, o salário médio foi de $\$ 6.245$ no terceiro trimestre do ano passado, segundo dados do INDEC.

Deram um salto

A carne e os legumes foram os itens que mais subiram em

fevereiro; $12,1 \%$ e $17,3 \%$

respectivamente.

$\mathrm{O}$ quilo de patinho nos quatro supermercados custa, em média, $\$ 80$, embora em dois deles chegue perto dos $\$ 90$. Esse corte, fora do programa Preços Cuidados 6 , é o que mais aumentou em fevereiro: $18,6 \%$.

A costela custa $\$ 57,17$ na média, depois do aumento de $12,9 \%$ em um mês.

O frango subiu 3,2 e o presunto $9,2 \%$. Visto que a carne moída está dentro do programa Preços Cuidados, praticamente não teve modificações (a variação mensal é

\section{4 de $0,6 \%$ )}

Uma família gasta hoje \$1.044,28 somente na carne de que precisa em um mês.
Por sua parte, os legumes subiram $17,3 \%$ como consequência das chuvas que afetaram as zonas produtivas.

Aumentaram o tomate perita (o quilo vale em média $\$ 19,95)$, a alface (custa \$29,63), a laranja (custa $\$ 12,02$ o quilo) e a acelga (vale \$12,59), principalmente.

Pouco cuidados

No setor do armazém, laticínios, higiene e limpeza é onde se encontra a maioria dos Preços Cuidados, porém, em Córdoba, só se aplicaram em 53 produtos.

No primeiro mês da implementação, não conseguiram mudar a tendência crescente dos preços. Pelo contrário, o armazém está 5,3\% mais caro e os artigos de limpeza $6,9 \%$ para cima.
Os laticínios são os únicos que baixaram de preço em fevereiro, porque o leite Sancor diminuiu o preço, segundo o acordado com a Nação.

Armazém. Em fevereiro, subiram a erva-mate, as bolachas e os ovos entre $13 \mathrm{e}$ $29,4 \%$. Somente o café, a Coca Cola e o pão se mantiveram estáveis.

Teve baixas no arroz e no tomate concentrado devido à presença de ofertas. Uma família destina, ao mês, \$910,28 aos produtos de armazém.

Laticínios. Baixaram 5,4\% pela queda do leite fluida. O leite integral Sancor diminuiu os preços depois do acordo e baixou $11,3 \%$. Possui o preço de começo de janeiro passado. O litro dessa marca custa $\$ 7,18$ e, em um dos supermercados não estava disponível, embora seja um Preço Cuidado. Um leite semelhante de $L a$

Serenísima custa quase \$10.

Higiene e limpeza. A subida no setor é de $6,9 \%$ na média. Os principais aumentos correspondem ao desodorante, ao detergente e ao sabão em pó. Baixaram os barbeadores e a cândida, porque voltou aos supermercados a marca tradicional, que é a mais barata, ausente nas gôndolas durante vários meses.

Fonte: www.lavoz.com.ar

\footnotetext{
${ }^{5}$ A notícia foi traduzida do espanhol para o português pela autora deste artigo.

${ }^{6}$ O programa Precios Cuidados é um programa de alcance nacional sob a coordenação do Ministério de Economia. Através desse programa, o governo fez acordos com muitas empresas produtoras de alimentos e higiene e limpeza. Aqueles produtos incluídos dentro do programa têm o preço fixado durante um período de tempo. Com essa iniciativa, o governo procura, basicamente, controlar o aumento de preços.
} 


\section{RELEVAMIENTO PROPIO}

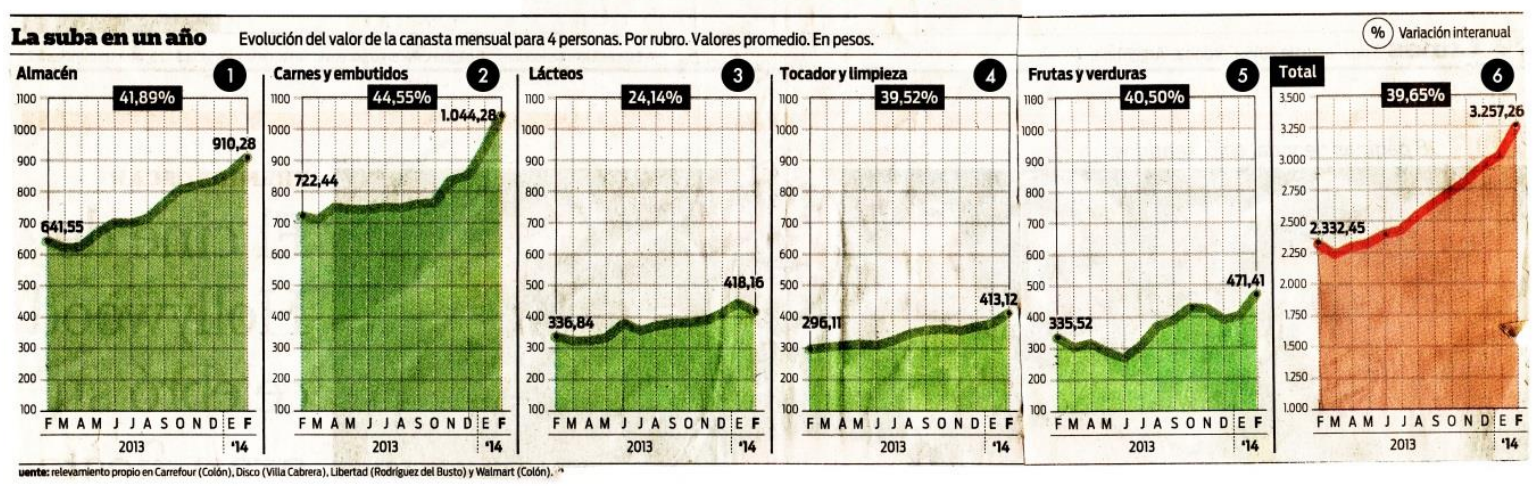

Figura 1: Gráficos da notícia do Jornal La voz del interior, utilizada para desenvolver a tarefa ${ }^{7}$

Fonte: www.lavoz.com.ar

Uma vez selecionada a notícia, Araceli, Liliana e Yanela elaboraram para os alunos um conjunto de perguntas centradas na interpretação de gráficos. Essa primeira versão da atividade foi discutida em uma reunião do grupo, quando Araceli destacou que as perguntas "estão um pouco desorganizadas. Eu ainda não encontro como agrupá-las segundo as coisas às quais se referem. Isso é o que está faltando" (Áudio, 1/6/2014). Percebe-se pela fala de Araceli, que a tarefa de organizar o trabalho não era linear ou simples, não se tratava de copiar algo previamente elaborado por outras pessoas. Elas eram as principais protagonistas na criação da atividade, e isso envolvia a tomada de decisões sobre múltiplos aspectos. Particularmente, era necessário construir uma certa organização para as perguntas incluídas. Tal preocupação levou o grupo a se envolver numa reflexão sobre a organização da atividade, trabalhando, principalmente, na análise detalhada de cada uma das perguntas que a compunham. Uma dessas perguntas, que indagava acerca de como era calculada a porcentagem 39,65\% que aparecia na parte superior do gráfico que representava a evolução do preço da cesta básica total (ver gráfico 6 na Figura 1), deu origem à seguinte discussão:

Araceli: É uma pergunta fácil de responder?

Damián: Para mim é interessante.

Vários: Sim!

[Discussão sobre como é calculada essa porcentagem]

Damián: E se você perguntasse: "o que significa essa porcentagem"?

Araceli: Pode ser. Eu tinha medo que [os estudantes] tentassem relacionar as porcentagens de cada um dos gráficos com a porcentagem final de alguma forma [Se refere às porcentagens que aparecem na parte superior dos gráficos de cada item da cesta básica (vide Figura 1)].

Mónica: E se eles tentassem, o que eles fariam? Usariam a média, por exemplo?

Araceli: Pode ser... Não tentei fazer isso.

[Vários membros calculam a média das porcentagens, obtendo como resultado 38,12]

\footnotetext{
7 Tradução para o português:

Levantamento próprio. A subida em um ano. Evolução do valor da cesta básica para quatro pessoas. Por item. Valores médios. Em pesos.

Os gráficos correspondem aos seguintes itens: 1) Armazém, 2) Carnes e frios, 3) Laticínios; 4) Higiene e limpeza; 5) Frutas e legumes e 6) Total.
} 
Melania: Bom, não está tão longe...

Araceli: É uma boa ideia o que o Damián falou, de perguntar "que significa a porcentagem", talvez os oriente mais do que perguntar "como calcular" (Áudio, $1 / 6 / 2014)$.

Esse episódio mostra os esforços de Araceli e do grupo como um todo para antecipar parte das múltiplas incertezas da prática docente durante o processo de planejamento. Particularmente a dúvida que preocupava Araceli dizia respeito ao grau de dificuldade da pergunta. Os aportes dos membros do grupo contribuíram em duas direções. Em primeiro lugar, Damián propôs o que, à primeira vista, pode parecer uma pequena mudança na redação: em lugar de centrar a pergunta no "cálculo", centrá-la no "significado" da porcentagem. Analisada em profundidade, essa mudança transforma a natureza da atividade. Assim, refletir sobre o significado da porcentagem vai além de simplesmente compreender o mecanismo pelo qual ela é calculada, visto que envolve também uma atividade de interpretação. Em segundo lugar, Mónica sugeriu continuar imaginando o caminho que poderiam seguir os alunos, se decidissem explorar a relação entre a porcentagem de aumento do preço total da cesta básica e a porcentagem de aumento de seus itens. Essa intervenção permitiu que os membros do grupo se envolvessem em um processo de análise do que poderia acontecer, se as propostas dos alunos - muitas vezes diferentes das esperadas pelo professor - fossem recuperadas, analisando aonde poderiam conduzir estes caminhos.

Em discussões como as apresentadas neste episódio, a atenção aos detalhes da formulação de cada pergunta reflete o esforço dos membros do grupo por começar a antecipar possíveis dificuldades e respostas dos alunos. Ademais, o exame minucioso de cada pergunta ajudou as professoras a explorar com minúcias quais possibilidades de aprendizagem cada enunciado oportuniza para os alunos. Essas são aprendizagens importantes, considerando que os membros do grupo eram professores iniciantes.

O seguinte episódio mostra outra das discussões em torno da atividade durante a mesma reunião:

Leticia: Trata-se de um tema que está em conflito hoje. Dá para fazer uma análise em relação a isso, a partir de um olhar crítico. Eles apresentam todos esses dados, mas não falam de onde eles os tiraram. Se foi um levantamento que fez La voz del interior, por que esses dados valeriam mais do que os do INDEC ${ }^{8}$ ? Eles falam que foram a quatro supermercados de Córdoba. O que eles estão olhando? Eles olham para tudo o que está incluído na cesta básica ou só [olham para] algumas coisas? ... Usando estatística podem ser feitas análises destacando coisas e ocultando outras. As coisas que baixaram de preço são mencionadas rapidamente.

Liliana: Certo. Isso também ajuda aos alunos para que, quando lerem uma notícia, percebam que estão presentes estas coisas, e que eles devem ser críticos e não acreditar diretamente no que é dito.

[Discussão sobre os itens incluídos na cesta básica e como é calculada pelo INDEC]

\footnotetext{
${ }^{8}$ INDEC é a sigla para se referir ao Instituto Nacional de Estatística e Censos da Argentina, organismo público encarregado de desenvolver todas as atividades estatísticas oficiais do país, entre elas, o cálculo do preço da cesta básica. O INDEC seria o equivalente, no Brasil, ao Instituto Brasileiro de Geografia e Estatística.
} 
DOI: https://doi.org/10.20396/zet.v26i3.8650646

Araceli: É bom aquilo que a Leti falou, de fazer uma interpretação da notícia, posso tentar falar com alguma professora da área de [Ciências] Sociais. (Áudio, 1/6/2014)

Esse diálogo mostra como a discussão dentro da comunidade foi fazendo emergir novos pontos de vista sobre a atividade. Assim, o trabalho com a notícia poderia ser aproveitado para introduzir os alunos na complexidade envolvida em elaborar dados estatísticos significativos para calcular o valor da cesta básica: analisar quais são os itens que compõem a cesta básica e por que; refletir sobre como tomar as amostras de preços, etc. Ademais, poderia ser aberto o debate sobre os usos políticos dos dados estatísticos, ajudando os alunos a desenvolver um sentido crítico na hora de interpretar dados estatísticos presentes em diferentes âmbitos de sua vida. A partir dessa proposta, Araceli começou a imaginar a possiblidade de trabalhar conjuntamente com professores de outras disciplinas dentro de sua escola. A discussão sobre se incluir ou não uma análise crítica da notícia nos levou a refletir acerca dos objetivos que estavam sendo imaginados para a atividade:

Mónica: Eu queria perguntar quais são os objetivos que você está colocando para esta atividade?

Araceli: Hum, agora não sei. Um pouco eu tinha colocado no documento que enviei para vocês.

[Lemos os objetivos que estavam enunciados no documento: Interpretar um gráfico que represente uma situação real [...] levando em conta os seguintes conteúdos matemáticos: função, domínio e imagem, pontos de corte com os eixos, crescimento e decrescimento, intervalos de positividade e negatividade, pontos de máximo e mínimo, absolutos e relativos]

Mónica: então estaríamos em "interpretar um gráfico que represente uma situação real".

Leticia: Sim, e têm alguns conteúdos que já estão sendo tratados, pontos de corte, crescimento e decrescimento...

Araceli: Variáveis.

Leticia: [Referindo-se ao listado de conteúdos] Variáveis, onde está?

Araceli: Não está! [Risos] [...]

Leticia: Domínio e imagem ficam fora? Não sei se pode ser trabalhado nesta situação.

Yanela: Eu estive pensando um pouco, tentando ver que perguntas poderíamos fazer com respeito ao domínio e foi muito difícil. (Áudio, 1/6/2014)

Através desses intercâmbios, o grupo se constituiu em um espaço onde Liliana, Yanela e Araceli analisaram e refinaram os objetivos propostos para a atividade, permitindo a reflexão aprofundada da prática que estava sendo imaginada. Assim, conseguiram incluir aqueles conteúdos que realmente poderiam ser desenvolvidos com as perguntas e excluir os que não eram mobilizados.

No que diz respeito ao planejamento, a participação no grupo fez com que Araceli, Liliana e Yanela explicitassem as incertezas e as dúvidas que emergiram, ao desenhar a tarefa, e que pudessem encontrar parceiros com os quais estabelecer interlocuções e problematizar a tarefa, revelando suas potencialidades e as diversas possiblidades a serem seguidas. Nesta direção, todos os membros da comunidade investigativa se comprometeram em práticas tais como a discussão do grau de dificuldade da tarefa, a antecipação de possíveis dificuldades dos estudantes, a exploração de propostas de resolução diferentes das esperadas, Zetetiké, Campinas, SP, v.26, n.3, set./dez.2018, p.441-463 
a modificação dos enunciados, a descoberta de novos pontos de vista sobre a tarefa e o refinamento dos seus objetivos. A participação nessas práticas envolvia, então, múltiplas aprendizagens para os professores iniciantes. Os aportes dos membros da comunidade investigativa contribuíram para outorgar o apoio didático-metodológico e afetivo para que as professoras iniciantes conseguissem projetar e antecipar uma prática docente engendrada a partir dos seus próprios interesses. O enunciado final da atividade, elaborado a partir das discussões no grupo, se mostra no Quadro 2.

Quadro 2 - Enunciado da atividade

Atividade:

1) Leiam atentamente a notícia do jornal e respondam às seguintes perguntas:

a. Quais variáveis vocês identificam em cada um dos gráficos apresentados pela notícia?

b. Entre quais valores varia o preço da cesta básica?

c. Em quais períodos o preço da cesta básica diminuiu? Nesse período, diminuíram os preços de todos os itens?

d. No último gráfico, como foram calculados os preços de fevereiro de 2013 e fevereiro de 2014? Qual o significado do $39,65 \%$ que aparece na parte superior do gráfico?

e. Quanto dinheiro precisava aproximadamente uma família de quatro pessoas para comprar a cesta básica em junho de 2013? Analisem item por item e depois contrastem com o gráfico do total.

f. Considerando o gráfico 5, descrevam em quais períodos houve um aumento do preço e em quais uma diminuição. Quais poderiam ser as causas desse fenómeno?

g. A notícia afirma: 'Nesse ano, a cesta já registra um incremento de 13\%'. Se vocês tivessem que fazer essa afirmação, quais elementos deveriam levar em consideração para obter esse dado?

h. Na notícia aparece uma análise discriminada dos itens armazém, laticínios, higiene e limpeza. Se vocês fossem o autor da notícia, como escreveriam uma análise referida ao item 'frutas e legumes'?

2) Realizar, por escrito, uma análise crítica da notícia levando em consideração aqueles aspectos que considerem relevantes, pontos de vista, opiniões, constatação com outras fontes de dados, etc.

Fonte: A autora

A sequência elaborada foi implementada em duas turmas de $6^{0}$ ano da Educação Secundaria9 (alunos de 17 anos) que estavam a cargo de Araceli. Liliana e Yanela também participaram das aulas, realizando observações e atuando como professoras colaboradoras dentro da sala de aula. Dessa maneira, a participação no grupo favoreceu que uma professora recentemente graduada da Licenciatura em Matemática - Liliana - e uma aluna do último ano da Licenciatura - Yanela - pudessem ter mais uma experiência em sala de aula, trabalhando colaborativamente com uma professora iniciante.

Durante a implementação, as três se envolveram em processos de registro da sua prática, que relataram da seguinte forma:

Nós três apontávamos as dúvidas mais frequentes, as diferentes respostas que apareciam, as dificuldades, etc., e depois de cada aula nos reuníamos para conversar sobre o que cada uma de nós tinha observado e gravávamos essas conversas com o celular. É importante ressaltar o caráter reflexivo destas conversas que nos permitiam repensar sobre nossa própria prática. (Losano et al., 2017, p. 67)

\footnotetext{
${ }^{9}$ A educação obrigatória em Argentina compreende a Educação Inicial (2 anos de duração - Alunos de 4 e 5 anos), Educação Primaria (6 anos de duração - Alunos de 6 a 11 anos) e Educação Secundaria (6 anos de duração - Alunos de 12 a 17 anos).
}

Zetetiké, Campinas, SP, v.26, n.3, set./dez.2018, p.441-463 
A produção de registros da própria prática envolve múltiplas aprendizagens, visto que requer explicitar, enunciar, explicar, discutir, negociar e procurar soluções para o que aconteceu na sala de aula. Particularmente, através da construção desses registros, as professoras iniciantes podiam discutir sobre as respostas e as dificuldades dos alunos, os aspectos positivos e negativos da tarefa e imaginar estratégias para melhorar o trabalho nas próximas aulas. Portanto, registrar envolve um esforço para reificar o que muitas vezes passa despercebido ou se perde na rapidez e na urgência da prática docente cotidiana. Justamente a partir destas reificações é possível começar a desenvolver reflexões aprofundadas sobre a prática, as quais ajudaram as professoras iniciantes a orientar suas ações para as próximas aulas, e também colaboraram para o desenvolvimento de uma postura crítica e aguçada da sua própria prática docente.

Um outro ponto importante em relação aos registros de classe é que, dentro do grupo, tínhamos acordado que as professoras produziriam esses registros, mas não tinha sido dada nenhuma indicação concreta sobre como elaborá-los nem quais suportes utilizar. Yanela, Araceli e Liliana criaram sua própria maneira de registar a prática, combinando gravações com o celular e anotações escritas com lápis e papel. Elas escolheram quais aspectos registrar, segundo as preocupações e as prioridades de cada uma. Logo, o trabalho colaborativo das três professoras em sala de aula possibilitou o desenvolvimento de diferentes observações sobre o trabalho dos alunos e sobre a aula como um todo. Ao compartilhar estas visões diferentes - nas reuniões depois de cada aula ou nas reuniões com o grupo todo - elas iam ampliando o olhar sobre suas práticas docentes.

Depois da implementação, uma reunião do grupo foi dedicada a compartilhar, analisar e refletir sobre a experiência vivida. Durante esse encontro, Yanela, Liliana e Araceli comentaram sobre a produção dos alunos em cada uma das perguntas que compunham a atividade. Quando estávamos discutindo sobre as respostas à pergunta "Em quais períodos o preço da cesta básica diminuiu?”, surgiu o seguinte diálogo entre Melania e Araceli:

\footnotetext{
Araceli: As respostas eram bastante...

Melania: Bastante o quê?

Araceli: Curtas [Risos].

Melania: Eles não entravam em detalhes?

Araceli: Sim, respondendo assim...

Melania: Bom. Mas se você perguntou isso, eles responderam isso. Eles são assim! ...Araceli: As perguntas limitaram muito as respostas e não permitiram que eles [os alunos] se debruçassem. Era uma lista de perguntas ... Eu sentia que eles não estavam trabalhando a notícia como um problema, eram gráficos com números e eles iam respondendo às perguntas e era só isso. (Áudio, 9/9/2014).
}

O diálogo entre Melania e Araceli mostra como o grupo se constituiu em um espaço onde era possível compartilhar as primeiras experiências na prática e iniciar a problematização das impressões e das visões dos alunos que emergiram delas. Araceli e Melania começam descrevendo certas práticas habituais dentro de uma aula de matemática: a resposta a uma pergunta de matemática se reduz a escrever poucas palavras ou números. Tomar contato com essas práticas dos alunos, legitimadas durante anos de resolver exercícios 
e problemas de resposta única, é um fato desafiador para todo docente, e produzir sentido sobre elas pode ser particularmente difícil para um professor iniciante. $\mathrm{O}$ episódio mostra como a participação em um grupo colaborativo pode ser uma oportunidade fértil para empreender essa tarefa. Em lugar de simplesmente responsabilizar os alunos pelas suas respostas "curtas", a discussão no grupo permitiu refletir sobre o papel da tarefa - que elas mesmas tinham elaborado - para produzir este tipo de respostas. O episódio ensinou a Araceli e Melania tecer conexões entre a natureza das perguntas propostas e a natureza das respostas dos alunos, ou seja, entre a prática do docente e as práticas dos estudantes. A partir da reflexão compartilhada, Araceli começou a perceber que, se ela queria que seus alunos realizassem uma análise global da notícia, que incluísse os números e as porcentagens, e também os procedimentos mobilizados para a construção da resposta e os aspectos sociais e políticos envolvidos na notícia, ou seja, para que seus estudantes "problematizassem a notícia”, talvez seria necessário apresentar-lhes perguntas diferentes

A discussão sobre as respostas ao item e) da atividade (vide Quadro 2) possibilitou continuar refletindo e trazer novos pontos de vista sobre as práticas desenvolvidas pelos estudantes na hora de elaborar uma resposta em matemática. É importante assinalar que o valor do preço de cada item da cesta básica ou do total para junho de 2013 deve ser estimado a partir do gráfico e, visto que a linha de traço dela é bastante grossa (vide Figura 1), as professoras tinham previsto que os alunos poderiam ter dificuldades para estimar os valores. De fato, decidiram incluir essa pergunta como uma oportunidade para que os alunos pudessem pensar como deve ser desenhado um gráfico que permita uma leitura apropriada dos dados. Araceli e Yanela apresentaram da seguinte maneira o trabalho dos alunos:

Araceli: Não tinham problemas para fazer o cálculo. Procuravam no gráfico, somavam [os valores de cada item] e pronto. O que eu não vi em nenhum dos trabalhos foi que depois de somar eles constatassem com o gráfico final [se refere ao gráfico que representa o valor total da cesta básica]

Yanela: Outra dúvida que [os estudantes] tinham era qual valor tomar ...não sabiam se tomar o de cima [se refere a considerar o valor que se obtém tomando a borda superior da linha no gráfico] ou a borda de baixo, ou mais ou menos no meio. Houve um grupo que tomou o de cima e quando somaram [os valores de todos os itens da cesta básica] perceberam que não obtinham o mesmo valor que aqui [aponta para o gráfico do valor total do preço da cesta básica], eles tinham obtido um valor superior. Araceli: Ah! Que bom!

Yanela: Então eles voltaram a fazer as aproximações ... Mas tinham coisas que [os alunos] discutiam oralmente que eram importantes que depois eles não escreviam

Araceli: Se todas essas decisões que eles conversavam entre eles e com a gente, estivessem plasmadas [no escrito]! Mas não, elas não estão. (Áudio, 9/9/2014).

Esse episódio destaca uma das possiblidades abertas pelo fato da implementação envolver duas professoras colaborando em sala de aula: Yanela conseguiu observar aspectos do trabalho dos alunos para os quais Araceli não havia se atentado. Uma aula é um momento de grande complexidade, onde muitas práticas e discursos acontecem simultaneamente, e é comum que muitos deles passem despercebidos para o professor. Contar com outro colega dentro da sala de aula não somente ajuda com a gestão das atividades, mas também aporta um 
outro olhar que, quando compartilhado, auxilia a enriquecer a visão sobre a aula, os estudantes, a tarefa, etc. Particularmente, a observação de Yanela fez com que Araceli enxergasse que, ao menos alguns de seus alunos, tinham realizado estimações e contrastado o resultado, tal como ela imaginava. Além disso, o episódio mostra Yanela e Araceli se deparando com outra prática dos alunos legitimada dentro da escola: as discussões desenvolvidas dentro de cada grupo - que podem incluir ou não ao professor - permanecem em formato oral, não sendo necessário registrá-las por escrito, principalmente durante uma aula de matemática. Essas reflexões nos levaram a discutir sobre a importância, e as dificuldades de trabalhar com os alunos a escrita em matemática:

Araceli: Eles estão acostumados que na aula de matemática as respostas têm que ter coisas numéricas, então, todas as respostas tinham que ter um resultado ou calcular alguma coisa. Isso foi muito forte.

Leticia: Poderíamos pensar que contexto poderia nos ajudar a transformar este contrato tão estabelecido.

Araceli: Tem que ser uma coisa gradual. Tem que começar antes, nos cursos anteriores. Para eles era a primeira vez ...nos anos anteriores isto não é feito. Para eles era completamente novo e, obviamente, eles vão responder como sempre respondem.

A reflexão sobre o tipo de respostas produzidas pelos alunos favoreceu que Araceli percebesse a vinculação entre sua prática e as práticas de outros professores em diversos momentos da trajetória dos alunos. Em certa medida, compreender a influência da trajetória prévia dos alunos nas práticas que eles desenvolvem na sala de aula pode ajudar a atenuar as inseguranças e as ansiedades dos professores iniciantes, visto que envolve entender o seu papel - e sua responsabilidade - dentro de um trajeto que se iniciou muitos anos antes de eles tomarem contato com os alunos. Ao mesmo tempo, a reflexão desenvolvida no grupo fez que Araceli ressaltasse a necessidade de construir acordos com os outros colegas, de maneira a oferecer trajetórias de aprendizagem diferentes para os estudantes. No meu ponto de vista, essa é uma evidência da emergência de um alinhamento crítico da professora iniciante com certas práticas estabelecidas na sua escola.

A análise realizada permite dizer que, no que tange à reflexão sobre a prática $a$ posteriori, o grupo foi um espaço onde as professoras iniciantes puderam expressar e compartilhar os contrastes e as tensões entre a prática que tinham imaginado ao planejar e o que efetivamente foi possível realizar dentro da sala de aula. Desse modo, a reflexão sobre a prática implicou que Yanela, Araceli e Liliana pudessem relatar seus dilemas e suas inquietações, ao encontrar-se com certas práticas dos estudantes estabelecidas e legitimadas dentro da escola. O grupo se envolveu em discussões, visando refletir e produzir sentido sobre tais inquietações e dilemas, que acabaram evidenciando importantes aprendizagens para os professores iniciantes. Particularmente, Araceli entendeu que as práticas dos alunos para responder às particularidades da vida cotidiana dentro da escola são produzidas ao longo dos anos e que existem vinculações entre elas e a prática docente. Essas aprendizagens são indicadores de que as três professoras iniciantes começaram a desenvolver uma postura 
questionadora e crítica sobre sua própria prática docente, o que é indício importante de desenvolvimento profissional.

Liliana, Yanela e Araceli ressaltaram diversos aspectos da experiência vivenciada em diferentes documentos produzidos por e para o grupo. Na sua narrativa, Araceli referiu-se à experiência com as seguintes palavras: "Eu me senti confortável, apoiada, ajudada e isso faz com que tenha coragem para fazer, para reproduzir o que já foi feito, para encarar novos desafios" (Narrativa Araceli, 2015). A participação no grupo parece ter mobilizado Araceli para continuar propondo pequenas transformações nas tarefas apresentadas aos seus alunos e, consequentemente, nas práticas de ensinar e aprender que se desenvolvem na sua sala de aula e na sua escola. Liliana escolheu ressaltar o trabalho em equipe: "O processo de elaboração, de implementação das atividades e de registro do acontecido geram a necessidade de trabalhar em equipe" (Narrativa Liliana, 2015). Essa professora, que ainda não tinha começado a atuar na escola, conseguiu imaginar, a partir do vivenciado, o caráter indispensável do trabalho com seus pares dentro da escola. No capítulo de livro produzido pelo grupo, Yanela e Liliana destacaram como essa experiência tinha lhes possibilitado recuperar parte do seu passado:

[Durante a FI] tínhamos vivenciado uma experiência de caraterísticas similares ... quando juntas desenvolvemos nosso estágio supervisionado trabalhando de maneira colaborativa. A possibilidade de trabalhar novamente desta maneira, dessa vez com Araceli, ... nos permitiu reviver parte da experiência do estágio e adquirir novas ferramentas para nosso futuro trabalho como professoras. (Losano et al., 2017, p. 66).

Assim, a participação no grupo ajudou Yanela e Liliana a recuperar parte das suas experiências vividas durante a formação inicial, construindo novos sentidos para elas e, a partir destas aprendizagens, projetar-se ao futuro como professoras em exercício.

\section{Tecendo algumas conclusões}

A análise narrativa focada no processo de planejamento, implementação e reflexão da tarefa de interpretação de gráficos dentro da comunidade investigativa evidencia diversas aprendizagens dos professores iniciantes. Muitas delas vinculadas a aspectos didáticopedagógicos das tarefas para a sala de aula, entre eles, aprender a refinar os objetivos de uma tarefa, explorar resoluções diferentes das esperadas, analisar distintos aspectos que podem ser trabalhados a partir de uma mesma situação, antecipar dificuldades dos alunos. Outras aprendizagens estão relacionadas com a criação de registros da própria prática: a escrita emerge como uma maneira de refletir sobre o trabalho realizado em sala de aula. Finalmente, aprendizagens vinculadas com a reflexão sobre a prática, ao estabelecer vinculações entre as decisões e as ações tomadas pelos professores, as práticas dos alunos e o contexto de trabalho cotidiano nas escolas. Essas aprendizagens, situadas na participação na comunidade investigativa, constituem uma valiosa contribuição para que os professores iniciantes enfrentem os processos epistemológicos, sociais e pessoais envolvidos nos primeiros anos de seu exercício profissional (Winslow et al., 2009). 
Nossa análise vai ao encontro dos resultados obtidos por Rocha e Fiorentini (2009), ao analisar o desenvolvimento profissional de professores que se iniciam no exercício profissional. Segundo esses autores, o desenvolvimento profissional nos primeiros anos na docência se revela como "um processo tenso..., mas também rico e significativo, pela possibilidade de constituição e transformação profissional do professor, tendo em vista os diferentes interlocutores que este encontra nesta fase" (p. 144). Particularmente, este estudo mostra como o processo de constituição profissional pode ser apoiado e potencializado, quando o professor iniciante encontra, numa comunidade investigativa, interlocutores com os quais pode dividir seus medos e inseguranças, assim como discutir estratégias e trocar experiências. Vemos, aqui, evidências de que o desenvolvimento profissional de professores iniciantes que participam de grupos colaborativos pode ser compreendido como um movimento que reúne passado, presente e futuro. Ao participar em grupos colaborativos, esses professores conseguem refletir sobre as primeiras experiências como docentes que estão vivenciando no presente, compartilhando dúvidas e dilemas e problematizando suas próprias práticas e as práticas estabelecidas nas escolas. Ao mesmo tempo, conseguem recuperar e ressignificar parte das experiências vividas no passado, particularmente, durante a sua formação inicial. Finalmente, a participação no grupo possibilita que os professores iniciantes se projetem ao futuro, imaginando o tipo de práticas docentes que gostariam de desenvolver na sua sala de aula, se sentindo acompanhados e apoiados no propósito de tentar alcançá-las. A participação nesses grupos possibilitaria, então, transitar de uma maneira frutífera pelos sentimentos de sobrevivência e descoberta próprios do início do exercício profissional.

A análise realizada também revela que a participação numa comunidade investigativa possibilita que os professores iniciantes comecem a desenvolver um alinhamento crítico em relação às práticas estabelecidas na escola: dentro da comunidade investigativa o professor iniciante compreende que não é possível - nem sequer desejável - mudar todas as práticas escolares "da noite para o dia" e que, sendo ele um recém-chegado na comunidade da escola onde começa a trabalhar, terá que conviver e se alinhar com muitas delas. Contudo, o desenvolvimento de uma postura crítica e questionadora da própria prática dentro de uma comunidade investigativa impulsiona os professores iniciantes a continuar buscando - e muitas vezes encontrando - brechas para produzir novas transformações nas práticas de ensinar e aprender matemática na escola.

Assim como os estudos de Gama (2007, 2009) e Rocha e Fiorentini (2009), nossos resultados ajudam a valorizar as oportunidades de formação continuada que proporcionem apoio aos professores iniciantes e os ajudem a se tornarem protagonistas dos seus processos de socialização e constituição profissional. Particularmente, este estudo mostra a potencialidade das comunidades investigativas para o desenvolvimento profissional dos professores iniciantes, pois propicia que esses profissionais, muitas vezes colocados em posições vulneráveis ou periféricas dentro das escolas, comecem a desenvolver uma postura crítica da sua própria prática e conectem seu trabalho com o contexto social e cultural onde trabalham. 
DOI: https://doi.org/10.20396/zet.v26i3.8650646

\section{Referências}

Bakhtin, M. (1984). Problems of Dostoevsky's Poetics. (C. Emerson, Ed.), Theory and History of Literature (Vol. 8). University of Minnesota Press.

Bjuland, R., Cestari, M. L., \& Borgersen, H. E. (2012). Professional mathematics teacher identity: Analysis of reflective narratives from discourses and activities. Journal of Mathematics Teacher Education, 15(5), 405-424. https://doi.org/10.1007/s10857-0129216-1

Cabrera, D. (2015). Acercamiento básico al trabajo de modelización: Actividad experimental para el trabajo de funciones. XXXVIII Reunión de Educación Matemática. Santa Fe, Argentina.

Cecchetto, L., Coirini, A., \& Colazo, Y. (2015). Análisis de gráficos en contextos de semirealidad: experiencia en un grupo colaborativo. XXXVIII Reunión de Educación Matemática. Santa Fe, Argentina.

Clandinin, D. J., \& Connelly, F. M. (2000). Narrative Inquiry: Experience and Story in Qualitative Research. Jossey-Bass Publishers.

Day, C. (1999). Developing Teachers: The Challenges of Lifelong Learning. Bristol: Taylor \& Francis.

Ferreira, A. (2008). O trabalho colaborativo como ferramenta e contexto para o desenvolvimento profissional: compartilhando experiências. In A. M. Nacarato \& M. Paiva (Eds.), A formação do professor que ensina matemática: perspectivas e pesquisas (pp. 149-166). Belo Horizonte: Autêntica.

Fiorentini, D. (2009). Quando acadêmicos da universidade e professores da escola básica constituem uma comunidade de prática reflexiva e investigativa. In D. Fiorentini, R. Grado, \& R. G. S. Miskulin (Eds.), Práticas de formação e de pesquisa de professores que ensinam matemática (pp. 121-156). Campinas: Mercado de Letras.

Fiorentini, D. (2013). Learning and Professional Development of the Mathematics Teacher in Research Communities 1. Sisyphus - Journal of Education, 1(3), 152-181.

Fiorentini, D., \& Crecci, V. (2013). Desenvolvimento Profissional docente: Um Termo Guarda-Chuva ou um novo sentido à formação? Formação Docente. Revista Brasileira de Pesquisa Sobre Formação Docente, 5(8), 11-23.

Fiorentini, D., \& Carvalho, D. L. (2015). O GdS como lócus de experiências de formação e aprendizagem docente. In D. Fiorentini, F. L. Pereira Fernandes, \& D. L. Carvalho (Eds.), Narrativas de Práticas e de aprendizagem docente em matemática (pp. 15-37). São Carlos: Pedro \& João Editores.

Gama, R. (2007). Desenvolvimento profissional com apoio de grupos colaborativos: o caso de professores de matemática em início de carreira. Doutorado em Educação. Universidade Estadual de Campinas.

Gama, R. (2009). Professores iniciantes e o desenvolvimento profissional: um olhar sobre pesquisas acadêmicas brasileiras. In D. Fiorentini, R. C. Grando, \& R. G. S. Miskulin (Eds.), Práticas de formação e de pesquisa de professores que ensinam matemática (pp. 125-146). Campinas: Mercado de Letras. 
Gama, R., \& Fiorentini, D. (2008). Identidade de Professores Iniciantes de Matemática que Participam de Grupos Colaborativos. Horizontes, 26(2), 31-43.

Gellert, U., Becerra, R., \& Chapman, O. (2013). Research Methods in Mathematics Teacher Education. In M. A. Clements, A. J. Bishop, C. Keitel, J. Kilpatrick, \& F. K. S. Leung (Eds.), Third International Handbook of Mathematics Education (pp. 327-360). Springer New York. https://doi.org/10.1007/978-1-4614-4684-2

Goldenberg, M. (2011). A arte de pesquisar. Rio de Janeiro: Record.

Goos, M. (2005). A sociocultural analysis of the development of pre-service and beginning teachers' pedagogical identities as users of technology. Journal of Mathematics Teacher Education, 8(1), 35-59. https://doi.org/10.1007/s10857-005-0457-0

Goos, M., Arvold, B., Bednarz, N., DeBlois, L., Maheux, J., Morselli, F., \& Proulx, J. (2009). School experience during pre-service teacher education from the students' perspective. In R. Even \& D. Loevenberg Ball (Eds.), The professional education and development of teachers of mathematics (pp. 83-91). New York: Springer.

Guérios, E. (2005). Espaços intersticiais na formação docente: indicativos para a formação continuada de professores que ensinam matemática. In D. Fiorentini \& A. M. Nacarato (Eds.), Cultura, formação e desenvolvimento profissional de professores que ensinam matemática (pp. 128-151). São Paulo: Musa.

Jaworski, B. (2008). Building and sustaining inquiry communities in mathematics teaching development. In K. Krainer \& T. Wood (Eds.), Participants in mathematics teacher education (pp. 309-330). Rotterdam: Sense Publishers.

Kieran, C., Krainer, K., \& Shaughnessy, J. M. (2013). Linking research to practice: teachers as key stakeholders in mathematics education research. In M. A. Clements, A. Bishop, C. Keitel, J. Kilpatrik, \& F. Leung (Eds.), Third international handbook of mathematics education (pp. 361-391). New York: Springer.

Lave, J., \& Wenger, E. (1991). Situated learning. Legitimate peripheral participation. Cambridge: Cambridge University Press.

Lerman, S. (2009). Student teachers' experiences and early years of teaching. In R. Even \& D. Loewenberg Ball (Eds.), The professional education and development of teachers of mathematics (p. 71). New York: Springer.

Losano, L., Cabrera, D., \& Giannone, M. (2015) Construyendo e implementando actividades para el aula con TICs: reflexiones generadas dentro de un grupo colaborativo. Presentação em Painel. VII Escuela de Didáctica de la Matemática. 1 ao 3 de outubro de 2015. Buenos Aires, Argentina.

Losano, L., Cabrera, D., Cecchetto, L., Coirini, A., Colazo, Y., \& Giannone, M. (2017). Desarrollo professional de profesores de matemática: experiencias de participación en un grupo colaborativo durante los primeiros años de ejercicio docente. In D. Fregona, S. Smith, M. Villarreal, \& F. Viola (Eds.), Formación de profesores que enseñan matemática y práticas educativas en diferentes escenários: Aportes para la educación matemática (pp. 51-83). Córdoba: Editorial de la Universidad Nacional de Córdoba.

Losano, L., Fiorentini, D., \& Villarreal, M. E. (2018). The development of a mathematics teacher' s professional identity during her first year teaching. Journal of Mathematics Teacher Education, 21(3), 287-315. https://doi.org/10.1007/s10857-017-9364-4 
Passos, C. L. B., Nacarato, A. M., Fiorentini, D., Miskulin, R. G. S., Grando, R. C., Gama, R. P., ... Melo, M. (2006). Desenvolvimento profissional do professor que ensina Matemática: Uma meta-análise de estudos brasileiros. Quadrante, XV (1 e 2), 193-219.

Ponte, J. P. (2006). Estudos de caso em educação matemática. Bolema, 25, 105-132.

Ponte, J. P. (1998). Da formação ao desenvolvimento profissional. In Actas do Profmat98 (pp. 27-44). Lisboa: APM.

Riessman, C. K. (2002). Analysis of Personal Narratives. In J. A. Gubrium, J. F., Holstein (Ed.), Handbook of Interview Research: Context and Method (pp. 695-711). Sage.

Riessman, C. K. (2005). 1 Narrative Analysis. Narrative, Memory \& Everyday Life, 1-8. https://doi.org/10.2307/1252124

Rocha, L., \& Fiorentini, D. (2009). Percepções e reflexões de professores de matemática em início de carreira sobre seu desenvolvimento profissional. In D. Fiorentini, R. C. Grando, \& R. Miskulin (Eds.), Práticas de formação e de pesquisa de professores que ensinam matemática (pp. 125-14). Campinas: Mercado de Letras.

Rockwell, E. (2009). La experiencia etnográfica. Buenos Aires: Paidós.

Skovsmose, O. (2014). Um convite à educação matemática crítica. Campinas: Papirus.

Wagner, J. (1997). The unavoidable intervention of educational research: a framework for reconsidering research-practitioner cooperation. Educational Researcher, 26(7), 13-22.

Walshaw, M. (2012). Reformulations of mathematics teacher identity and voice. Journal of Mathematics Teacher Education, 15(2), 103-108. https://doi.org/10.1007/s10857-0129206-3

Wenger, E. (1998). Communities of practice: learning, meaning, and identity. Cambridge University Press.

Winslow, C., Bergsten, C., Butlen, D., David, M., Gómez, P., Goos, M., ... Wood, T. (2009). First years on teaching. In R. Even \& D. Loewenberg Ball (Eds.), The professional education and development of teachers of mathematics. The 15th ICMI Study (pp. 93101). New York: Springer. 